\title{
Assessment of COVID-19 Preparedness on Obstetrics and Gynecology Practices in Nepal
}

\author{
Raj Deb Mahato ${ }^{\star}$ Gopal Gurung², Amit Deo ${ }^{1}$ Surya B. Parajuli ${ }^{3}$
}

\section{Author Info:}

'Lecturer, Department of Obstetrics and Gynecology; Birat Medical College and Teaching Hospital, Tankisinuwari, Morang,

2Lecturer, Department of Dental Surgery; Birat Medical College and Teaching Hospital, Tankisinuwari, Morang, Nepal

${ }^{3}$ Assistant Professor, Department of Community Medicine, Birat Medical College and Teaching Hospital, Tankisinuwari, Morang, Nepal

\section{Corresponding Author:}

Dr. Raj Deb Mahato

Email/Contact/ ORCID: rajdeb.mahato700@gmail.com

https://orcid.org/0000-00028015-4098]

\begin{abstract}
Background: The Coronavirus Disease (COVID-19) is an infectious disease caused by SARS-CoV-2 virus. The Coronavirus transmitted between people through direct contact with infected people and indirect contact with infected surface and object. The practicing Doctor is at more risk of infection with Coronavirus. The WHO declared the Coronavirus infection as a pandemic on March 11, 2020. COVID-19 pandemic is disrupting health services worldwide. The objective of this study was to assess COVID-19 preparedness on Obstetrics and Gynecology practices in Nepal.

Methods: We conducted a web-based cross-sectional study from 5 July to 20 July 2020. We collected 136 responses from Obstetrics and Gynecology consultants practicing at different hospitals of Nepal through google forms. Data were analyzed by using SPSS version 22.

Results: Among 136 Obstetrics and Gynecology Consultants, most of participants were spacing ANC visits for low-risk pregnancy (86\%), refer patients to Corona designated center if suspected of coronavirus infection (72.8\%), did not ask their patients for COVID-19 test before any procedures (69.04\%) and triage and risk screening for COVID-19 for each patient (69.1\%). Proper personal protective measure was not available in most of the centers. Most of the centers has working guidelines for COVID-19. Most of the routine activities were resumed by most of the participants. Most of the hospitals had isolation wards (71.3 \%) but most of the hospitals didn't have isolated Labour rooms $(61.8 \%)$ and isolated operation theatres (62.5\%). Only a few participants $(15.4 \%)$ had received specific training regarding COVID-19.

Conclusion: Proper personal protective equipment was available in few centers and very few participants had received special training for COVID-19. Most of the hospitals had working guidelines for COVID-19. Most participants didn't test their patients for COVID-19 before any surgical procedures. Most of the participants follow the proper protective measures during practice.

Keywords: Coronavirus, Gynaecology, Obstetrics, Nepal, Practice
\end{abstract}

\section{Quick Response (QR)} Code

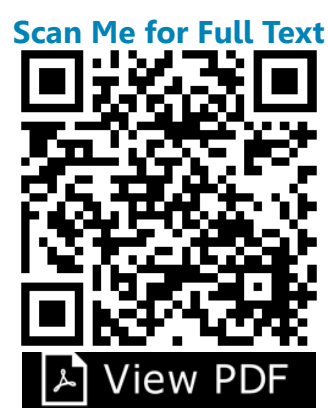

\section{Article Info}

Received: 27 September 2020; Accepted: 8 November 2020; Published Online: 9 November 2020 How to cite this article in Vancouver Style?

Mahato RD, Gurung G, Parajuli S. Assessment of COVID-19 Preparedness on Obstetrics and Gynecology Practices in Nepal. Europasian J Med Sci. 2020; 2(COVID-19 Special Issue): 23-25. https://doi.org/10.46405/ ejms.v2i2.210

\section{Disclaimer}

\section{Conflict of Interest: None Declared;}

\section{Source of Support: Nil}

Copyright: (C) 2020 by author(s). This is an open access article distributed under the terms of the Creative Commons Attribution International License 4.0 (http://creativecommons.org/licenses/by/4.0/) which permits unrestricted use, distribution, and reproduction in any medium, provided the original work is properly cited.

\section{Publisher's Note}

The Europasian Journal of Medical Sciences (EJMS) (www.europasianjournals.org) is an official Journal of Nirvana Psychosocial Care Center \& Ressearch Institute (www.nirvanapscc.com). The Journal as well as publisher remain neutral with regards to any jurisdictional claims in any published articles, its contents and the institutional affiliations of the authors. 


\section{INTRODUCTION}

The COVID-19 pandemic presents specific challenges to Obstetrics and Gynecology services. WHO has declared the Coronavirus infections as a pandemic on March 11, 2020. Many countries have implemented social distancing rules and partial and full lockdown. To meet the demand for healthcare services, a rapid response is needed to efficiently allocate resources for patients care and maintain the safety and wellbeing of healthcare professionals. ${ }^{1}$ In this condition, healthcare systems had to modify their organization to cope with the emergency, caused by COVID-19 pandemic. Aim is to optimize resources and minimize a further dissemination of the coronavirus infections. ${ }^{2}$ Dealing with coronavirus infections is challenging because of its asymptomatic presentation and the high-risk of infection to healthcare provider. ${ }^{3}$ Poor strategical planning and the lack of rapid COVID-19 testing at the point of treatments have been a major problem for healthcare professionals in Nepal. Pregnant women are susceptible to severe infection and hypoxia due to changes in the cardiorespiratory and immune systems in pregnancy at the same time delay in diagnosis of COVID-19 infections in those women with only upper respiratory tract symptoms such as sore throat and nasal congestion. ${ }^{4}$ Asymptomatic patients can present to Obstetrician and Gynecologist so necessary precautions are required to manage that kind of patients. As lockdown started in Nepal, most of the outdoor services were closed and emergency patients were examined in the emergency and managed accordingly. In the COVID-19 pandemic the Obstetrics and Gynecology have started to practice according to various guidelines and have adopted modifications in their practices. The preparedness during COVID-19 pandemic in Obstetrics and Gynecology practice is not known in the present context So, we conducted this study with the objective to assess COVID-19 preparedness on Obstetrics and Gynaecology practices in Nepal.

\section{MATERIALS AND METHODS}

We conducted a web-based cross-sectional study from 5 July to 20 July 2020. Questionnaire was prepared in google forms. Questionnaire was divided into four parts, the first part contained questions about current practice, the second part dealt with changes to Obstetrics and Gynecology practices. Third part contained questions about personal preventive measures and the fourth part dealt with special training to combat COVID-19.
Questionnaire internet links were sent to members of Nepal society of Obstetrics and Gynecology (NESOG) practicing in Nepal through email, WhatsApp, Viber and Facebook messenger and responses were collected. Ethical clearance was taken from the Institutional Review Committee of Birat Medical College Teaching Hospital. Informed web-based consent was taken from all the participants before their responses. MS excel was used for data entry and data was analyzed by using SPSS version 22

\section{RESULTS}

Questionnaire links were sent to 223 Obstetrics and Gynecology consultants practicing at different hospitals of Nepal in which 136 (60.98\%) participants responded to questions. Almost all the participants (99.3\%) resumed their service. $63.2 \%$ of the participants are performing both Emergency and Elective cases and $36.8 \%$ of the participants perform only Emergency operation. $59.6 \%$ of the participants practice phone consultation (teleconsultations) or video consultation during COVID-19 pandemic. $72.8 \%$ of the participants are referring patients to COVID-19 designated center, selected by the government of Nepal if suspected of coronavirus infection. Around two third of the participants (69.1\%) are triaging and risk screening for COVID-19 for each patient. $60.3 \%$ of the participants are performing elective surgery and $17.6 \%$ of the participants have postponed elective surgery (Table 1).

Table 1: Current Practice $(n=136)$

\begin{tabular}{|c|c|c|}
\hline Characteristics & Response & n (\%) \\
\hline Department open & Yes & 135(99.3) \\
\hline \multirow{2}{*}{ Operation } & $\begin{array}{l}\text { Emergency \& } \\
\text { Elective }\end{array}$ & $86(63.2)$ \\
\hline & $\begin{array}{l}\text { Emergency } \\
\text { only }\end{array}$ & $50(36.8)$ \\
\hline $\begin{array}{l}\text { Practicing phone } \\
\text { consultation or video } \\
\text { consultation }\end{array}$ & Yes & 81 (59.6) \\
\hline $\begin{array}{l}\text { Referring patients } \\
\text { to Corona Centre if } \\
\text { suspected of corona }\end{array}$ & Yes & $99(72.8)$ \\
\hline $\begin{array}{llr}\begin{array}{l}\text { Triaging and } \\
\text { screening }\end{array} & \text { risk } \\
\text { COVID-19 for } \\
\text { patient }\end{array}$ & Yes & $94(69.1)$ \\
\hline Elective surgery & Yes & $82(60.3)$ \\
\hline
\end{tabular}


Table 2: Changes to Obstetrics and Gynecology services $(n=136)$

\begin{tabular}{l|l|l|}
\hline Characteristics & Response & n (\%) \\
\hline $\begin{array}{l}\text { Telling patients not to } \\
\text { come for regular follow } \\
\text { unless it's emergency }\end{array}$ & Yes & $120(88.2)$ \\
\hline $\begin{array}{l}\text { Routine antenatal care } \\
\text { service }\end{array}$ & Yes & $131(96.3)$ \\
\hline $\begin{array}{l}\text { Testing patient for } \\
\text { COVID-19 prior to any } \\
\text { procedure }\end{array}$ & Yes & $42(30.96)$ \\
$\begin{array}{l}\text { Spacing the ANC visits } \\
\text { for the low-risk patients }\end{array}$ & Yes & $117(86)$ \\
\hline $\begin{array}{l}\text { Wearing PPE during any } \\
\text { procedure }\end{array}$ & Yes & $33(24.3)$ \\
\hline $\begin{array}{l}\text { Availability of hospital } \\
\text { COVID 19 guidelines }\end{array}$ & Yes & $95(69.9 \%)$ \\
\hline
\end{tabular}

Toal of $88.2 \%$ of the participants told their patients not to come for regular follow ups unless it's an emergency. Almost all the participants (96.3\%) start providing routine antenatal care service. 60.3 $\%$ of the participants do not test their patients of coronavirus infection before any procedure and in $8.8 \%$ places the test kit is not available. $86 \%$ of the participants spacing the routine ANC visits for the low-risk pregnancy. Most of the participants (53.7\%) don't use PPE during any surgical procedure and in $22.1 \%$ of places PPE is not available. Most hospitals (69.9\%) had COVID-19 working guidelines (Table 2).

Protective measures like PPE are only available in $19.1 \%$ of hospitals. Only surgical masks are available in more than half of the centers. $81.6 \%$ of the participants wash their hands before and after touching patients. Most participants (59.6\%) wore gloves before touching patients. Almost all of the participants (93.4\%) avoid touching their eyes, nose and mouth to prevent coronavirus contamination. PPE is available in only $60.3 \%$ Hospitals. Alcoholbased hand sanitizer is available in $94.9 \%$ of Hospitals. Only $71.3 \%$ of hospitals have isolation wards. Around two thirds of hospitals didn't have an Isolated labour room (61.8\%) and Isolated operation theatre (62.5\%) (Table 3).

Specific training regarding COVID-19 was received by only $15.4 \%$ of the participants. Almost none of the participants are getting any incentive for practicing during COVID-19 pandemic. only 2.2 $\%$ of the participants are getting some kind of incentive for practicing during COVID-19 pandemic (Table 4).

\begin{tabular}{|c|c|c|}
\hline Characteristics & Response & n (\%) \\
\hline \multirow{3}{*}{ Protective measure } & KN95 mask & 38 (27.9) \\
\hline & PPE & $26(19.1)$ \\
\hline & $\begin{array}{l}\text { Surgical } \\
\text { mask }\end{array}$ & $72(52.9)$ \\
\hline $\begin{array}{l}\text { Washing hand before and } \\
\text { after touching patients }\end{array}$ & Yes & 111(81.6) \\
\hline $\begin{array}{l}\text { Wearing gloves before } \\
\text { touching patients }\end{array}$ & Yes & $81(59.6)$ \\
\hline $\begin{array}{l}\text { Avoiding touching the } \\
\text { eyes, nose and mouth }\end{array}$ & Yes & $127(93.4)$ \\
\hline Availability of PPE & Yes & $82(60.3)$ \\
\hline $\begin{array}{l}\text { Alcohol-based hand } \\
\text { sanitizer in your hospital }\end{array}$ & Yes & $129(94.9)$ \\
\hline Isolation ward & Yes & $97(71.3)$ \\
\hline Isolated labour room & Yes & $52(38.2)$ \\
\hline Isolated operation theatre & Yes & $51(37.5)$ \\
\hline
\end{tabular}

Table 4: Training and Incentive $(n=136)$

\begin{tabular}{|l|l|l|}
\hline Characteristics & Response & $\mathbf{n}(\%)$ \\
\hline $\begin{array}{l}\text { Training regarding } \\
\text { COVID-19 }\end{array}$ & Yes & $21(15.4)$ \\
\hline $\begin{array}{l}\text { Incentive for working } \\
\text { during pandemic }\end{array}$ & Yes & $3(2.2)$ \\
\hline
\end{tabular}

\section{DISCUSSION}

We performed a comprehensive overview Obstetrics and Gynecology practice during COVID-19 pandemic in Nepal. Most of the participants resumed their routine activities during COVID-19 pandemic so that health services began across the nation with some modification in practice. Preventive measure is followed by most of the participants. Only around one third of centers provide personal protective equipment (PPE) and most centers provide only surgical masks. This is inconsistent with the WHO recommendations for the use of personal protective equipment (PPE) in 
health care. ${ }^{5}$ Even alcohol-based hand sanitizer is not available in all hospitals. All of the participants don't Wash their hands before and after touching patients which is inconsistent with the WHO guideline. Washing hand kills viruses that may be present on hands. ${ }^{6}$ Avoiding touching their eyes, nose and mouth is practiced by most of the participants which is consistent with WHO guideline. Hands can pick up viruses and contaminated hands can transfer the virus to eyes, nose or mouth. From there, the virus can enter in the body. ${ }^{6}$ All of the participants not wearing gloves before touching patients which is inconsistent with WHO guideline which recommends that wearing gloves reduce the contamination of hands with blood and other body fluids and to reduce the risk of coronavirus transmission to Doctors and dissemination of virus from the Doctors to the patient as well as from one patient to other patients. ${ }^{7}$ Only 15.4 $\%$ of the participants received specific training regarding COVID-19. The special training regarding COVID-19 can increase professional knowledge and improve the practical skills of Doctors. ${ }^{8}$ Only $2.2 \%$ of the participants get some kind of incentive for working during COVID-19 pandemic. Incentives and bonuses positively motivate the practicing Doctors during COVID-19 pandemic. Most of the participants (60.3\%) didn't test for COVID-19 before any surgical procedure. COVID-19 testing gives us important information to ensure the safety of patients and health professionals. For patient safety, most of the participants spacing ANC visit for low risk pregnancy which reduces the risk of exposure. Around half of the participants didn't practice teleconsultations. Teleconsultations are a safe and effective way to evaluate the patients suspected of coronavirus infections and assess the patient's diagnosis, treatment and minimizing the risk of disease dissemination. Most Doctors triaging and risk screening for COVID-19 for each patient and referring patients to COVID-19 Centre if suspected of coronavirus infection this will help to protect general Hospital patients, staff and Doctors from coronavirus infection. Most of the hospitals had isolation wards but didn't have isolated Labour rooms and isolated operation theatre. Isolation of patients helps Doctors, other healthcare professionals and healthcare institutions to sue the appropriate principles of infection prevention while providing services in healthcare institutions for patients with suspected or proven coronavirus infections. ${ }^{9}$ Around one third of Hospital didn't have any working guidelines for COVID-19. Guideline provide clear policy guidance for timely health system preparedness and readiness to respond to the COVID-19 pandemic and frame work for timely, efficient and effective response to the COVID-19 pandemic. ${ }^{10}$

\section{CONCLUSION}

Proper personal protective equipment was available in few centers and very few participants have received special training for COVID-19. Most participants didn't test their patients for COVID-19 before any surgical procedures. Obstetrician and Gynecologist have modified their practices however they need adequate amounts of resources, training, incentives to provide quality Obstetrics and Gynaecology care to their patients during COVID-19 pandemic. The isolated Ward, isolated labour room and isolated operation theatre must be arranged to prevent COVID-19 transmission.

\section{REFERENCES}

1. Wang CJ, Ng CY, Brook RH. Response to COVID-19 in Taiwan: big data analytics, new technology, and proactive testing. JAMA 2020;32(14):1341-2. Google Scholar | JAMA

2. Daniele A. et.al. Impact of the COVID-19 pandemic on Urology Residency Training in Italy. Minerva Urologica e Nefrologica. April, 2020. | Google Scholar | ResearchGate

3. Chang D, Xu H, Rebaza A, Sharma L, Dela Cruz CS. Protecting health-care workers from subclinical coronavirus infection. Lancet Respir Med 2020;8:e13| Google Scholar

4. Guan W, Ni Z, Hu Y, et al. Clinical characteristics of coronavirus disease 2019 in China. N Engl J Med 2020 | Google Scholar

5. World Health Organisation; Geneva: 2020. Rational use of personal protective equipment for coronavirus disease 2019 (COVID-19). Accessed on $26^{\text {th }}$ July 2020. [ Link]

6. Infection prevention and control of epidemic-and pandemic-prone acute respiratory infections in health care, Geneva: World Health Organization; 2014 Google Scholar | FULLTEXT

7. WHO guidelines on hand hygiene in health care: first global patient safety challenge clean care is safer care. Accessed on $26^{\text {th }}$ July 2020. [Link]

8. Li L, Xv Q, Yan J. COVID-19: the need for continuous medical education and training. Lancet Respir Med. 2020;8(4):e23. | Google Scholar

9. Nepal Medical Council. Nepal Medical Council interim guidance for infection prevention and control when COVID-19 is suspected: interim guidance. Accessed on $26^{\text {th }}$ July 2020. [Link]

10. WHO.int/news-room/feature-stories/detail/aguide-to-who-s-guidance. Accessed on $26^{\text {th }}$ July 2020. [Link] 